\title{
Tracking nickel oxide reduction in solid oxide cells via ex-situ ptychographic nano-
} tomography

De Angelis, Salvatore; Jørgensen, Peter Stanley; Tsai, Esther Hsiao Rho; Holler, Mirko; Fevola, Giovanni; Bowen, Jacob R.

Published in:

Materials Characterization

Link to article, DOI:

10.1016/j.matchar.2020.110183

Publication date:

2020

Document Version

Peer reviewed version

Link back to DTU Orbit

Citation (APA):

De Angelis, S., Jørgensen, P. S., Tsai, E. H. R., Holler, M., Fevola, G., \& Bowen, J. R. (2020). Tracking nickel oxide reduction in solid oxide cells via ex-situ ptychographic nano-tomography. Materials Characterization, 162, [110183]. https://doi.org/10.1016/j.matchar.2020.110183

\section{General rights}

Copyright and moral rights for the publications made accessible in the public portal are retained by the authors and/or other copyright owners and it is a condition of accessing publications that users recognise and abide by the legal requirements associated with these rights.

- Users may download and print one copy of any publication from the public portal for the purpose of private study or research.

- You may not further distribute the material or use it for any profit-making activity or commercial gain

- You may freely distribute the URL identifying the publication in the public portal 


\title{
Tracking Nickel Oxide Reduction in Solid Oxide Cells via Ex-situ Ptychographic Nano- Tomography
}

Salvatore De Angelis ${ }^{a, b}$, Peter Stanley Jørgensen ${ }^{a}$, Esther Hsiao Rho Tsai ${ }^{b c}$, Mirko Holler ${ }^{b}$, Giovanni Fevola $^{a}$, and Jacob R. Bowen ${ }^{a}$

a) Department of Energy Conversion and Storage, Technical University of Denmark

(DTU), Frederiksborgvej 4000, Denmark

S.D. Angelis, P.S.Jørgensen: psjq@dtu.dk, G.Fevola: gfev@dtu.dk, J. R. Bowen: jrbo@dtu.dk

b) Paul Scherrer Institute (PSI),

5232 Villigen, Switzerland

S.D. Angelis: salvatore.de-angelis@psi.ch (present address), M. Holler: mirko.holler@psi.ch

c) Brookhaven National Laboratory Bldg. 735, Center for Functional Nanomaterials

Upton, NY 11973-5000, USA

E. H. R. Tsai: etsai@bnl.gov (present address)

\section{Corresponding author:}

Jacob Ross Bowen

Department of Energy Conversion and Storage, Technical University of Denmark

(DTU), Frederiksborgvej 4000, Denmark

Email: jrbo@dtu.dk

\begin{abstract}
In solid oxide cell (SOC) electrodes, nickel oxide reduction is a fundamental step occurring during the initial stages of cell operation. The reduction procedure is considered to be crucial in producing the final fuel electrode microstructure. This work studies the reduction reaction occurring in a SOC fuel electrode by means of X-ray ptychographic nanotomography. The same microstructure is
\end{abstract}


analyzed in its pristine state and after $1 \mathrm{~h}$ of reduction at $850^{\circ} \mathrm{C}$, in dry hydrogen. The microstructure evolution is discussed in terms of changes in volume fractions, surface areas, and connectivity of the different constituent materials. The pore network in the unreduced cermet is revealed to be fully isolated, implying that reduction proceeds inwards from the edges of the sample towards the center. For the given experimental conditions we report that reduction is complete after $1 \mathrm{~h}$ of treatment but the resulting nickel network is not yet percolated and detached from the yttria-stabilized zirconia.

\section{Keywords}

solid oxide cell; Ni-YSZ; nanotomography, ptychography; electrode; reduction; 3D reconstruction

\section{Introduction}

Solid oxide cells (SOC) are promising electrochemical devices able to efficiently convert chemical energy to electrical energy and vice-versa. Among the advantages of SOC technology is the use of inexpensive materials and the flexibility of using a large variety of fuels [1-3] (e.g $\mathrm{CO}, \mathrm{H}_{2}$ and $\mathrm{CH}_{4}$ ). The state-of-the-art SOC fuel electrode design is based on porous ceramic-metal (cermet) composite, made of yttria-stabilized zirconia (YSZ) and metallic Ni. During production, NiO particles are sintered together with the YSZ. Subsequently, the $\mathrm{NiO}$ oxide is reduced to metallic Ni during the first stages of the cell operation [4].

$\mathrm{NiO}$ reduction results in a volume reduction of $\sim 41 \%$ during the conversion of $\mathrm{NiO}$ to $\mathrm{Ni}[1]$. As a consequence, new porosity is created leading to the formation of additional active sites (triple phase boundaries). In previous works, it has been reported that different reduction conditions lead to different cell microstructure [4-6]. It is also shown that the morphology of the initial microstructure after reduction, influences the long-term nickel coarsening [7]. Therefore, a deeper understanding of the nickel reduction in real Ni-YSZ electrodes is crucial for designing long-lasting SOC fuel electrodes. 
Dynamical observation of $\mathrm{NiO}$ reduction has been performed by neutron radiography $[8,9]$, environmental scanning electron microscopy (ESEM) [10] and more recently, by environmental transmission electron microscopy (ETEM) $[11,12]$. ETEM analysis can provide precious information, ranging from changes in crystallographic orientation during reduction to following chemical reactions and morphological rearrangement at the nanometer scale. However, only 2D information can be obtained and strict requirements on the sample dimensions pose problems of samples representativeness.

In our previous works, we demonstrated that ptychographic X-ray computed tomography (PXCT) is a valuable tool for investigating the degradation mechanisms for SOCs and their effect on the cell active layer microstructure $[13,14]$.

Here, we present an ex-situ reduction experiment where the active NiO-YSZ layer of a SOC electrode is first analyzed in its pristine state and subsequently after reduction, with the aim to describe the reduction process in a real SOC electrode, under realistic conditions.

\section{Experimental}

The sample was prepared from a typical NiO-3YSZ (Yttria-Stabilized-Zirconia, mol. 3\% $\mathrm{Y}_{2} \mathrm{O}_{3}$ ) anode supported SOFC half-cell. Details of the cell production can be found elsewhere [15]. The sample was extracted from the functional layer (NiO-8YSZ), using precision polishing and FIB milling (CrossBeam X1540, Zeiss) to reach a final cylindrical pillar, $\sim 14 \mu \mathrm{m}$ in diameter and $\sim 15 \mu \mathrm{m}$ in height. The sample was mounted on a copper sample pin [16]. Details on the sample preparation can be found in our previous works [13,14].

The PXCT experiment was performed at the X12SA (cSAXS) beamline at the Swiss Light Source, Paul Scherrer Institute, Switzerland using the instrumentation described in [17]. The ptychographic 
measurement was carried out at $7.2 \mathrm{keV}$ with a scanning field of view of 19 by $11 \mu \mathrm{m}$. Diffraction patterns with sizes of $400 \times 400$ pixels were used in the ptychographic reconstruction, giving an object pixel size of $\sim 33.7 \mathrm{~nm}$. For each dataset, 500 projections over an angular range of $180^{\circ}$ were collected. The ptychographic and tomographic reconstruction followed the scheme described in [18].

The sample was initially imaged in its pristine state (NiO-YSZ) and then subsequently after reduction in a gas mixture of $5 \% \mathrm{H}_{2}$ and $95 \% \mathrm{~N}_{2}$. The sample was heated in a reducing atmosphere until it reached $850^{\circ} \mathrm{C}$. Subsequently, it was kept at $850^{\circ} \mathrm{C}$ for one hour and then cooled to room temperature. The treatment was conducted in a small custom-made tube furnace with a flow rate of $51 / \mathrm{h}$. The ramping rate was $10{ }^{\circ} \mathrm{C} / \mathrm{min}$ for both heating and cooling.

The two datasets were registered performing two rigid transformations. First, a coarse registration was performed by a manual alignment of the external shape of the reduced volume to the oxidized volume as well as the interface to the dense YSZ electrolyte. The volumes center of mass and axis of inertia were also registered. Secondly, a final rigid transformation was determined by the iterative closest point algorithm [19]. The raw volumes [20] were segmented using a 2D histogram thresholding procedure [13]. Microstructural quantitative characterization of particle sizes, interface areas and connectivity were calculated as described elsewhere [14,21]. For the connectivity analysis, regions of the analyzed phase are considered isolated if there is no connection between two opposite sides of the volume. Particle sphericity is a measure of how closely the shape of a particle approaches the shape of a perfect sphere. The sphericity $S$ of isolated particles is computed using equation 1:

$$
S=\frac{\pi^{\frac{1}{3}}\left(6 V_{p}\right)^{\frac{2}{3}}}{S_{p}}
$$

where $V_{p}$ is the volume of the particle and $S_{p}$ its surface area [22]. 
The registration of the two tomography datasets was performed using the commercial software Avizo 9.2.0 (Thermo Scientific ${ }^{\mathrm{TM}}$ ) for the manual coarse alignment. The MATLAB ${ }^{\circledR}$ implementation of the iterative closest point algorithm [23] was used for the final fine alignment. Other in-house MATLAB scripts were subsequently used for segmentation and microstructural characterization.

\section{Results and discussion}

Figure 1 shows the effect of the reduction on the microstructure, presenting the same slice from a sub-volume of the two spatially registered 3D datasets.
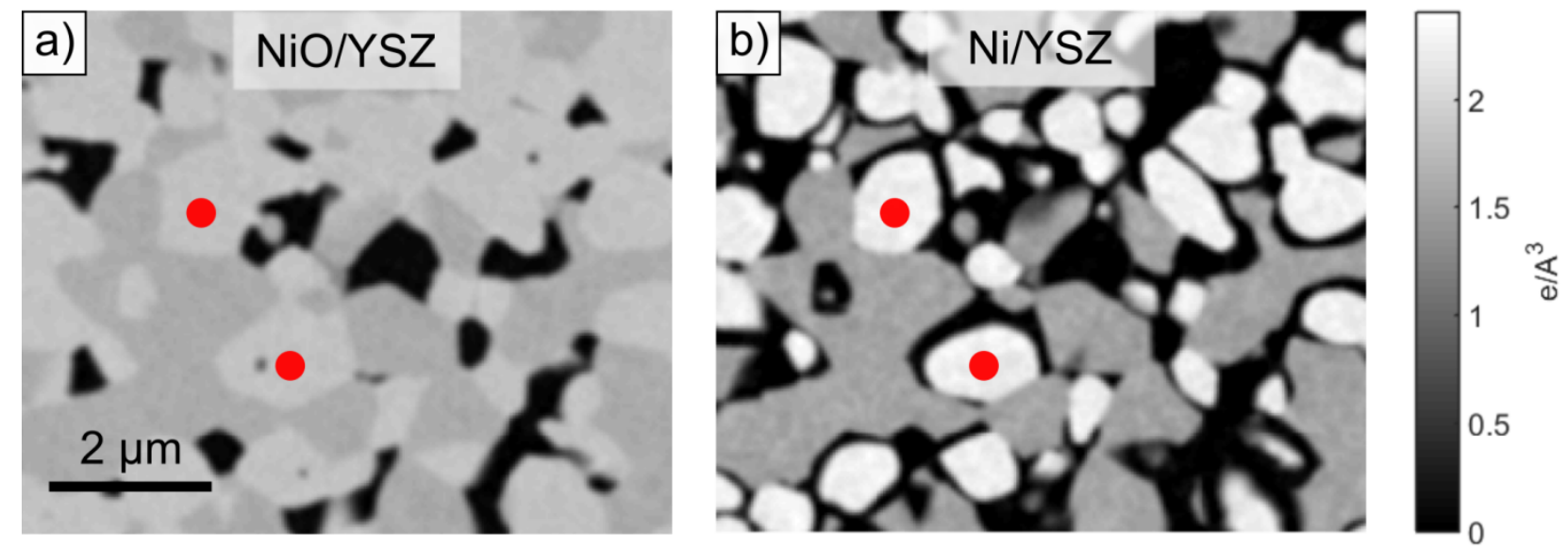

Figure 1. Representative slices from the spatially registered 3D volumes at identical locations in the electrode in the pristine state (a) and after reduction (b). In (a), the bright phase is NiO while in (b) the bright phase is metallic Ni. In (a) and (b) the grey phase is the YSZ while the black phase represents the pores. The red circles indicate example locations where the effect of reduction is visible. The color scale indicates the electron density.

The original microstructure in its pristine state (Figure 1a) is directly compared with the reduced state, after $1 \mathrm{~h}$ of treatment in $\mathrm{H}_{2}$ at $850^{\circ} \mathrm{C}$ (Figure $1 \mathrm{~b}$ ). The evolution of the chemical compositions of the constituent electrode materials can be analyzed calculating the mass density from the datasets as in [24]. Taking the corresponding peaks and the width at the half-height of the electron density histograms, we can calculate a mass density of $6.6 \pm 0.3 \mathrm{~g} / \mathrm{cm}^{3}$ for $\mathrm{NiO}$ and $5.8 \pm 0.4 \mathrm{~g} / \mathrm{cm}^{3}$ for the YSZ. These values are in good agreement with the theoretical mass densities of 6.6 and $6.1 \mathrm{~g} / \mathrm{cm}^{3}$ 
respectively. It is worth mentioning that, as expected, the measured YSZ electron density is identical in the two volumes. After reduction, we detect a mass density of $8.6 \pm 0.3 \mathrm{~g} / \mathrm{cm}^{3}$ for nickel, compared to $8.9 \mathrm{~g} / \mathrm{cm}^{3}$ of the theoretical value.

Using the Fourier shell correlation method according to [18], the isotropic 3D resolution of the pristine $(\mathrm{NiO} / \mathrm{YSZ})$ and reduced $(\mathrm{Ni} / \mathrm{YSZ})$ tomograms was determined to be $53.1 \mathrm{~nm}$ and $45.7 \mathrm{~nm}$ respectively. The lower resolution in the oxidized state is most likely due to the relatively lower electron density contrast between $\mathrm{NiO}$ and YSZ with respect to Ni and YSZ as revealed by Figure 1.

From Figure 1, for the given experimental conditions, the four following qualitative observations can be made:

1. The YSZ network remains unchanged during reduction

2. Additional porosity is formed during reduction

3. The resulting nickel particles appear rounded and detached from the YSZ network

4. The NiO network evolves into more fragmented Ni particles

For the analysis of the microstructure, the largest possible sub-volume $(\sim 7 \times 8 \times 10 \mu \mathrm{m})$ was extracted from a region close to the dense electrolyte. The microstructural parameters before and after reduction are summarized in Table 1.

The comparison reported in Table 1 is made on the same region of the electrode and it is, therefore, contrary to post-mortem analyses free from issues resulting from sample-to-sample variations. However, errors may arise from imperfect alignment and irreproducibility in the segmentation procedure. To provide an indication of the magnitude of these errors, we analyze the differences in the total YSZ surface area, which should remain unchanged after reduction. The relative difference in the YSZ total interface area is $5.5 \%$ which we attribute primarily to the difference in contrast level 
of $\mathrm{NiO} / \mathrm{Ni}$ relative to YSZ. From image analysis, we calculate a NiO/YSZ ratio of 54/46 \%, with an error of $\sim 6 \%$ compared to the $60 / 40 \%$ ratio based on production parameters. These volume averaged values of YSZ surface area and phase fractions are consistent with our previous works [13,20] and with other reports (e.g. $[15,25]$ ) on nominally identical pre-pilot production scale Ni-YSZ electrodes, implying that the manufacturing process produces microstructurally homogeneous electrodes.

Table 1. Calculated microstructure parameters for the sample in the pristine and reduced state.

\begin{tabular}{lccc}
\hline & $\begin{array}{c}\text { Pristine } \\
\text { NiO-YSZ }\end{array}$ & $\begin{array}{c}\text { Reduced } \\
\text { Ni-YSZ }\end{array}$ & $\begin{array}{c}\text { Relative } \\
\text { difference [\%] }\end{array}$ \\
\hline Phase fractions & 0.48 & 0.29 & -39.58 \\
(NiO/Ni) [-] & 0.41 & 0.41 & 0.00 \\
YSZ [-] & 0.11 & 0.30 & 172.73 \\
Pore [-] & 0.99 & 0.00 & - \\
Connected (NiO/Ni) $[-]^{*}$ & 0.99 & 0.99 & 0.00 \\
Connected YSZ [-] & 0.00 & 0.99 & - \\
Connected Pores $[-]^{*}$ & & & \\
\hline Volume-specific surface areas & 0.48 & 1.68 & 250.00 \\
Pore/YSZ interface $\left[\mu \mathrm{m}^{2} / \mu \mathrm{m}^{3}\right]$ & 0.54 & 1.42 & 162.96 \\
Pore/(NiO-Ni) interface $\left[\mu \mathrm{m}^{2} / \mu \mathrm{m}^{3}\right]$ & 1.52 & 0.41 & -73.03 \\
${\text { (NiO-Ni)/YSZ interface }\left[\mu \mathrm{m}^{2} / \mu \mathrm{m}^{3}\right]}_{\text {Pore interface }\left[\mu \mathrm{m}^{2} / \mu \mathrm{m}^{3}\right]}$ & 1.01 & 3.11 & 207.92 \\
YSZ interface $\left[\mu \mathrm{m}^{2} / \mu \mathrm{m}^{3}\right]$ & 1.99 & 2.10 & 5.53 \\
${\text { (NiO-Ni) interface }\left[\mu \mathrm{m}^{2} / \mu \mathrm{m}^{3}\right]}_{\text {TPB densities }}$ & 2.07 & 1.84 & -11.11 \\
\hline Total $\left[\mu \mathrm{m} / \mu \mathrm{m}^{3}\right]^{* *}$ & & & \\
Percolating $\left[\mu \mathrm{m} / \mu \mathrm{m}^{3}{ }^{*}\right.$ & 2.34 & 3.35 & 43.16 \\
\hline
\end{tabular}

* Relative difference not defined here.

** The pristine column refers to the density of the NiO-YSZ-Pore triple phase boundaries.

Table 1 shows that, upon reduction, there is a reduction in volume fraction from $48 \% \mathrm{NiO}$ to $29 \%$ $\mathrm{Ni}$, which is in excellent agreement with the difference in the molar volume of the two materials ( 0.604 ratio measured vs 0.600 theoretical). This confirms that the observation of change in electron density above is due to the completion of $\mathrm{NiO}$ reduction and does not indicate the presence of a large volume of sub-resolution nano-porosity. $\mathrm{NiO}$ reduction leads to the opening of new porosity, whos 
volume fraction increases from $11 \%$ in the pristine state to $30 \%$ in the reduced state in direct accordance with the change in molar volume of $\mathrm{NiO}$. The increase in the pore fraction explains the increase in the overall pore surface area and $\mathrm{Ni} /$ pore interface area. The considerable decrease of $\mathrm{NiO}-\mathrm{Ni} / \mathrm{YSZ}$ surface area confirms that the resulting nickel network is detached from the YSZ network. Interestingly, this finding is in agreement with what we reported in [14], where the nickel network was detached from the YSZ at the end of a redox cycle. Table 1 reports that the total TPB length increases when passing from the pristine to the reduced state. In the pristine state, the $\mathrm{NiO}$ network completely wets the YSZ and presents high connectivity (see Table 1) but has limited pore access. Contrarily, after reduction, the Ni microstructure is highly fragmented and not percolated (Table 1 and Figure 3b). The fragmentation of the resulting nickel network produces new TPBs. However, the lack of connectivity for the Ni phase electrochemically deactivates all the TPBs in the microstructure (see Table 1).

PXCT allows the determination of material electron density [24] and offers the unique capability of coupling information on chemical composition and morphology at high resolution in three dimensions. Ideal locations for monitoring the reduction reaction in a real SOC fuel electrode are isolated $\mathrm{NiO}$ particles. In fact, regions of interest (ROI) can be identified inside the electrode where the isolated particles are fully enclosed within the ROI. In this case, the effects of the chemical reaction on the particle morphology are independent of the conditions at the ROI boundary and quantitative information such as reduction in volume, surface area or particle sphericity can be precisely obtained. Figure 2 shows a study of the reduction reaction and the evolution of sphericity based on image analysis.

The reduction reaction follows the following formula: 


$$
\mathrm{NiO}+\mathrm{H}_{2} \rightarrow \mathrm{Ni}+\mathrm{H}_{2} \mathrm{O}
$$

where each mole of $\mathrm{NiO}$ is reduced to $\mathrm{Ni}$.
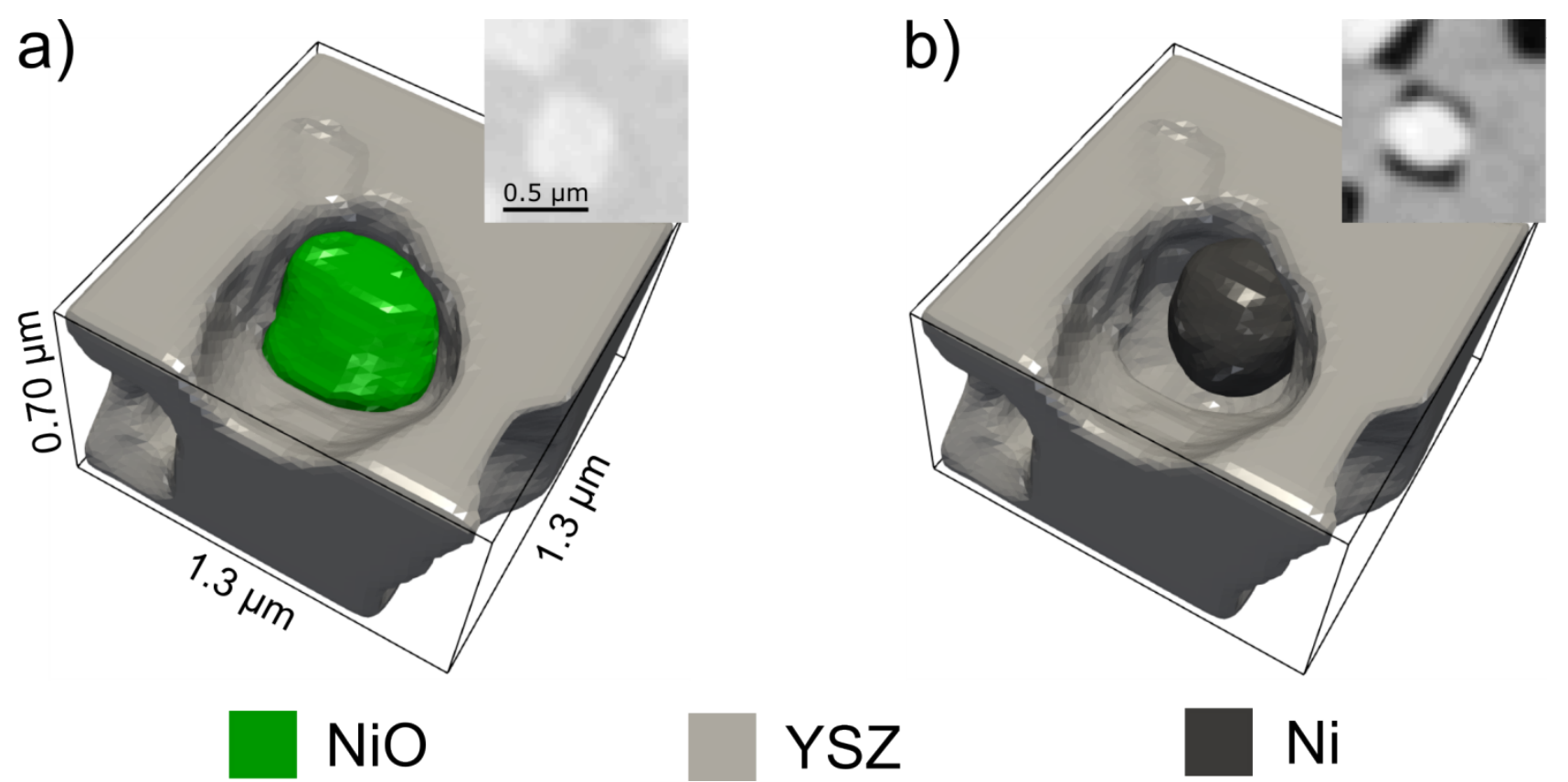

Figure 2. Evolution of one isolated particle from (a) pristine state to (b) reduced state. In (a) the YSZ is presented in grey, the $\mathrm{NiO}$ in green and the pores are transparent. In (b), Ni is presented in black. In the insets, the corresponding two-dimensional midplane slice from the raw data of each volume is shown.

The NiO particle presented in Figure 2 has a volume of $0.0961 \mu \mathrm{m}^{3}$ which decreases to $0.0536 \mu \mathrm{m}^{3}$ after reduction. Therefore, we can calculate a reduction in volume from $\mathrm{NiO}$ to $\mathrm{Ni}$ of $\sim 44 \%$, close to the theoretical value of $\sim 41 \%$. Regarding the evolution of particle sphericity, the particle presents a sphericity of 0.91 in its pristine state which evolves to 0.96 in the reduced state. This process testifies that, after reduction, the particle is free to reduce its interface area and evolves towards a spherical shape to minimize its surface energy. It should be noted that achieving a sphericity of 1.00 is unlikely due to the fact that the Ni particle remains bonded to the YSZ backbone and the probability that the local YSZ curvature matches the radius of the Ni particle is extremely low.

Information on how reduction proceeds within the sample can be obtained from the connectivity analysis of the pore phase in the pristine state. Figure 3 a shows a plot of the pore network in the 
pristine state where where each connected component of the pore network is colored individually. As reported in Table 1, all the pores present in the analyzed volume are isolated in the pristine state. Despite the fact that no pores cross the volume in any of the three cartesian directions, a significant number of pores are intersected by the volume boundaries as can be seen in Figure 3a. Whether these particles would be connected to technological scale features, such as inlet and outlet gas channels, in a functioning electrode in the pre-reduced state is thus unknown. As no pores connect opposite sides of the volume over distances between 7 to $10 \mu \mathrm{m}$ in any direction, it is expected that the majority of these pores are also disconnected from the sample extremities over significantly larger distances considering the relative homogeneity of the microstructure. During reduction, hydrogen molecules react with the exposed surface of the $\mathrm{NiO}$ network generating small Ni clusters [26]. Due to the volume contraction caused by reduction, new paths for $\mathrm{H}_{2}$ are created and the reaction proceeds inwards, producing a nano porous sponge-like structure within the newly formed Ni particles/network $[12,27]$
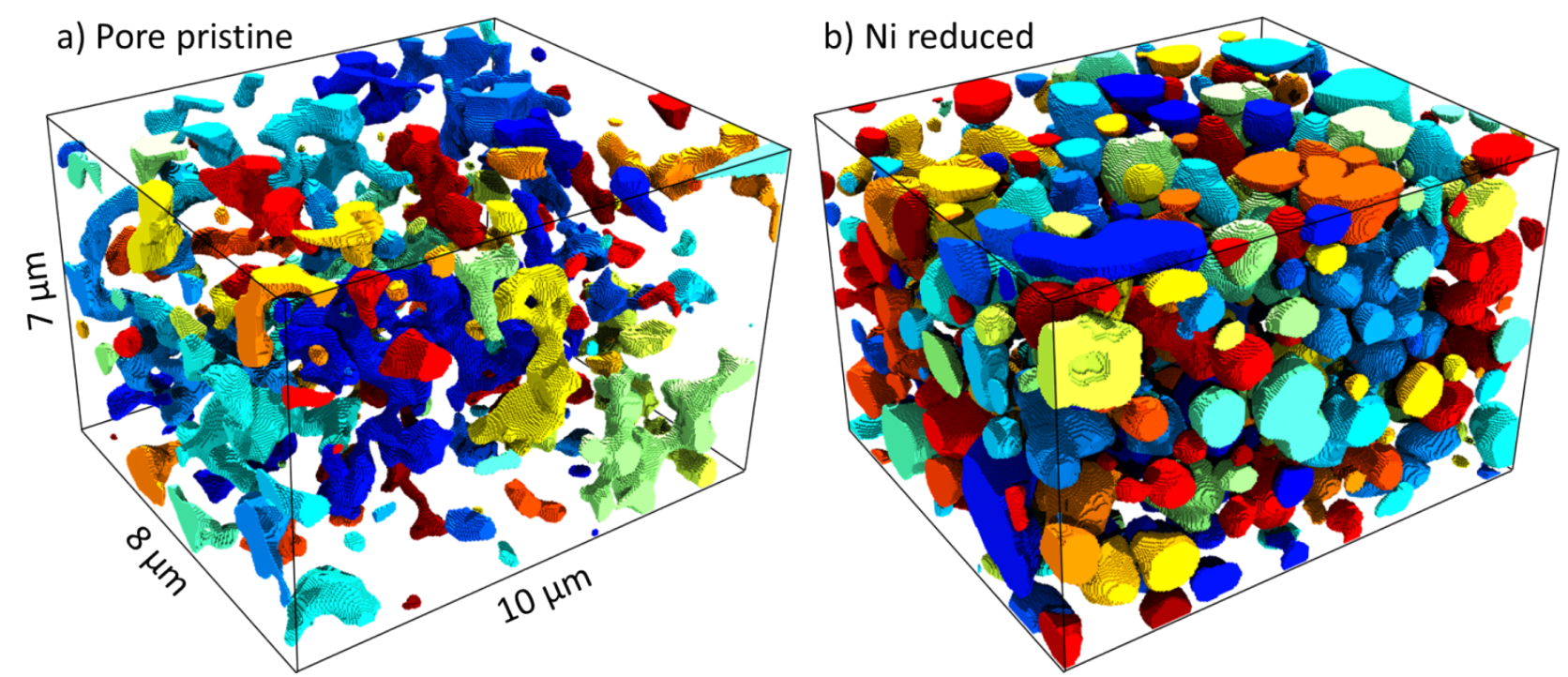

Figure 3. Surface rendering of the (a) pore network in the pristine state and (b) nickel network in the reduced state. Connected regions are colored individually.

Referring to the conditions of this experiment, since no pores transverse the entire volume there is no reducing gas flow to the center of the volume in the pristine state, only regions of the NiO network 
at the edge of the sample are in contact with hydrogen molecules. Therefore, we can conclude that the reaction proceeds inwards from the exterior towards the center of the sample. The contraction in volume due to the reduction of $\mathrm{NiO}$ to $\mathrm{Ni}$ opens new pathways for hydrogen molecules to reduce the inner regions of the sample until all the $\mathrm{NiO}$ is reduced to $\mathrm{Ni}$. Therefore, we speculate that there is a reaction front, which proceeds inwards from the outer regions of the sample and its properties could significantly affect the final Ni-YSZ microstructure.

Interestingly, Table 1 and Figure $3 \mathrm{~b}$ show that, after reduction, the resulting nickel network is not percolated. Therefore, the resulting microstructure is not suitable for a working solid oxide cell since the electron transport is hindered by the lack of electron pathways.

As discussed above, immediately after reduction, a nanoporous sponge-like nickel structure is formed $[10,12]$. Secondly, agglomeration occurs resulting in the formation of dense nickel particles [27]. For the conditions of this experiment, results show that the agglomeration leads to a non-percolating nickel network, mainly detached from the YSZ.

In order to gain additional information on the coarsening process immediately after reduction in addition to the kinetics of the reduction, time-dependent studies are required. Furthermore, monitoring the microstructure evolution during longer exposure times is required to assess how coarsening proceeds, leading to a more interconnected nickel network and thus an electrochemically active electrode.

\section{Conclusions}

The evolution of the microstructure of a NiO-YSZ cermet for SOC fuel electrodes was studied by PXCT. The sample was first analyzed in its pristine state and subsequently after $1 \mathrm{~h}$ of reduction at $850^{\circ} \mathrm{C}$, in dry hydrogen. 
The statistical analysis confirms that, after reduction, the pore fraction increases while the nickel volume decreases when compared to $\mathrm{NiO}$ in agreement with the theoretical molar volumes of $\mathrm{NiO}$ and $\mathrm{Ni}$. In the reduced state, there is less $\mathrm{Ni} / \mathrm{YSZ}$ interface area compared to the $\mathrm{NiO} / \mathrm{YSZ}$ area in the pristine state, testifying that the nickel network is mainly detached from the YSZ. Furthermore, compared to the $\mathrm{NiO}$ network, nickel microstructure is more fragmented leading to an increase in TPB density. However, nickel particles are fully isolated rendering all the TPBs electrochemically inactive. The connectivity analysis of the NiO-YSZ pore network revealed all pores within the volume are disconnected in the pristine condition. Since reduction occurs at the NiO exposed surface, the reaction is concluded to start from the sample exterior and proceed towards the center, suggesting the existence of a reaction front.

Analyzing the shape and volume of isolated $\mathrm{NiO}$ particles reveals that particle volume conforms to the molar volume contraction upon reduction and that isolated particles increase their sphericity to minimize their surface area.

Finally, for the conditions of this experiment, the resulting nickel network after $1 \mathrm{~h}$ of reduction was not percolated. Time-dependent studies are required to gain insights on the initial coarsening of nickel crystallites right after reduction. Furthermore, analysis of the microstructure after longer exposure times is necessary to asses if the coarsening proceeds, leading to a more connected nickel structure.

\section{Acknowledgments}

The authors would like to thank John Johnson for help in designing and building the sample environment, Ebtisam Abdellahi for the challenging sample preparation and Xavier Donath for his technical support at the cSAXS beamline. Financial support from "the allianCe for ImagiNg of Energy MAterials”, DSF-grant no. 1305-00032B via “The Danish Council for Strategic Research” is gratefully acknowledged. E. H. R. T was supported by the Swiss National Science Foundation grant 
number 200021_152554 and SNSF 200020_169623. Travel support for the synchrotron experiment through the DANSCATT grant from the Danish Council for Independent Research is gratefully acknowledged.

\section{Data Availability}

The raw data required to reproduce these findings are available to download from Zenodo.org (http://doi.org/10.5281/zenodo.2530732) [20]. The processed data required to reproduce these findings cannot be shared at this time as the data also forms part of an ongoing study. Segmented volumes, other processed data and analysis code is however available upon reasonable request.

\section{References}

[1] B. Shri Prakash, S. Senthil Kumar, S.T. Aruna, Properties and development of Ni/YSZ as an anode material in solid oxide fuel cell: A review, Renew. Sustain. Energy Rev. 36 (2014) 149179. https://doi.org/10.1016/j.rser.2014.04.043.

[2] S.P. Jiang, S.H. Chan, A review of anode materials development in solid oxide fuel cells, J. Mater. Sci. 39 (2004) 4405-4439. https://doi.org/10.1023/B:JMSC.0000034135.52164.6b.

[3] R.J. Kee, H. Zhu, A.M. Sukeshini, G.S. Jackson, Solid Oxide Fuel Cells: Operating Principles, Current Challenges, and the Role of Syngas, Combust. Sci. Technol. 180 (2008) 1207-1244. https://doi.org/10.1080/00102200801963458.

[4] S.L. Ebbehøj, T. Ramos, M. Mogensen, Impact of Reduction Parameters on the Initial Performance and Stability of Ni/(Sc)YSZ Cermet Anodes for SOFCs, ECS Trans. 45 (2012) 363-375. https://doi.org/10.1149/1.3701328.

[5] P.S. Jørgensen, S.L. Ebbehøj, A. Hauch, Triple phase boundary specific pathway analysis for quantitative characterization of solid oxide cell electrode microstructure, J. Power Sources. 279 (2015) 686-693. https://doi.org/10.1016/j.jpowsour.2015.01.054.

[6] M. Andrzejczuk, O. Vasylyev, I. Brodnikovskyi, V. Podhurska, B. Vasyliv, O. Ostash, M. Lewandowska, K.J. Kurzydłowski, Microstructural changes in NiO-ScSZ composite following reduction processes in pure and diluted hydrogen, Mater. Charact. 87 (2014) 159165. https://doi.org/10.1016/j.matchar.2013.11.011.

[7] Z. Jiao, N. Shikazono, Quantitative Study on the Correlation between Solid Oxide Fuel Cell Ni-YSZ Composite Anode Performance and Reduction Temperature Based on ThreeDimensional Reconstruction, J. Electrochem. Soc. 162 (2015) F571-F578. https://doi.org/10.1149/2.0721506jes.

[8] M.G. Makowska, M. Strobl, N. Kardjilov, H.L. Frandsen, I. Manke, M. Morgano, M.E. Lacatusu, S. de Angelis, E.M. Lauridsen, L.T. Kuhn, Investigating phase behavior and structural changes in $\mathrm{NiO} / \mathrm{Ni}$-YSZ composite with monochromatic in-situ 2D and static 3D neutron imaging, Phys. B Condens. Matter. (2017). https://doi.org/10.1016/j.physb.2017.11.026.

[9] M.G. Makowska, L.T. Kuhn, H.L. Frandsen, E.M. Lauridsen, S. De Angelis, L.N. Cleemann, M. Morgano, P. Trtik, M. Strobl, Coupling between creep and redox behavior in nickel - yttria 
stabilized zirconia observed in-situ by monochromatic neutron imaging, J. Power Sources. 340 (2017) 167-175. https://doi.org/10.1016/j.jpowsour.2016.11.059.

[10] J. Malzbender, E. Wessel, R.W. Steinbrech, Reduction and re-oxidation of anodes for solid oxide fuel cells, Solid State Ion. 176 (2005) 2201-2203. https://doi.org/10.1016/j.ssi.2005.06.014.

[11] Q. Jeangros, A. Faes, J.B. Wagner, T.W. Hansen, U. Aschauer, J. Van herle, A. HesslerWyser, R.E. Dunin-Borkowski, In situ redox cycle of a nickel-YSZ fuel cell anode in an environmental transmission electron microscope, Acta Mater. 58 (2010) 4578-4589. https://doi.org/10.1016/j.actamat.2010.04.019.

[12] A. Faes, Q. Jeangros, J.B. Wagner, T.W. Hansen, J.V. Herle, A. Brisse, R. Dunin-Borkowski, A. Hessler-Wyser, In situ Reduction and Oxidation of Nickel from Solid Oxide Fuel Cells in a Transmission Electron Microscope, ECS Trans. 25 (2009) 1985-1992. https://doi.org/10.1149/1.3205743.

[13] S. De Angelis, P.S. Jørgensen, E.H.R. Tsai, M. Holler, K. Kreka, J.R. Bowen, Three dimensional characterization of nickel coarsening in solid oxide cells via ex-situ ptychographic nano-tomography, J. Power Sources. 383 (2018) 72-79. https://doi.org/10.1016/j.jpowsour.2018.02.031.

[14] S. De Angelis, P.S. Jørgensen, V. Esposito, E.H.R. Tsai, M. Holler, K. Kreka, E. Abdellahi, J.R. Bowen, Ex-situ tracking solid oxide cell electrode microstructural evolution in a redox cycle by high resolution ptychographic nanotomography, J. Power Sources. 360 (2017) 520 527. https://doi.org/10.1016/j.jpowsour.2017.06.035.

[15] A. Hauch, S.D. Ebbesen, S.H. Jensen, M. Mogensen, Solid Oxide Electrolysis Cells: Microstructure and Degradation of the Ni/Yttria-Stabilized Zirconia Electrode, J. Electrochem. Soc. 155 (2008) B1184-B1193. https://doi.org/10.1149/1.2967331.

[16] M. Holler, J. Raabe, R. Wepf, S.H. Shahmoradian, A. Diaz, B. Sarafimov, T. Lachat, H. Walther, M. Vitins, OMNY PIN-A versatile sample holder for tomographic measurements at room and cryogenic temperatures, Rev. Sci. Instrum. 88 (2017) 113701. https://doi.org/10.1063/1.4996092.

[17] M. Holler, J. Raabe, A. Diaz, M. Guizar-Sicairos, C. Quitmann, A. Menzel, O. Bunk, An instrument for 3D x-ray nano-imaging, Rev. Sci. Instrum. 83 (2012) 073703. https://doi.org/10.1063/1.4737624.

[18] M. Holler, A. Diaz, M. Guizar-Sicairos, P. Karvinen, E. Färm, E. Härkönen, M. Ritala, A. Menzel, J. Raabe, O. Bunk, X-ray ptychographic computed tomography at $16 \mathrm{~nm}$ isotropic 3D resolution, Sci. Rep. 4 (2014). https://doi.org/10.1038/srep03857.

[19] P.J. Besl, N.D. McKay, Method for registration of 3-D shapes, in: 1992: pp. 586-606. https://doi.org/10.1117/12.57955.

[20] S. De Angelis, P.S. Jørgensen, E.H.R. Tsai, M. Holler, G. Fevola, J.R. Bowen, Tracking Nickel Oxide Reduction in Solid Oxide Cells via Ex-situ Ptychographic Nano-Tomography [Data set], (n.d.). https://doi.org/10.5281/zenodo.2530732.

[21] P.S. Jørgensen, K.V. Hansen, R. Larsen, J.R. Bowen, High accuracy interface characterization of three phase material systems in three dimensions, J. Power Sources. 195 (2010) 8168-8176. https://doi.org/10.1016/j.jpowsour.2010.06.083.

[22] H. Wadell, Volume, Shape, and Roundness of Quartz Particles, J. Geol. 43 (1935) 250-280. https://doi.org/10.1086/624298.

[23] Register two point clouds using ICP algorithm - MATLAB pcregistericp - MathWorks Nordic, (n.d.). https://se.mathworks.com/help/vision/ref/pcregistericp.html (accessed January 3, 2020). 
[24] A. Diaz, P. Trtik, M. Guizar-Sicairos, A. Menzel, P. Thibault, O. Bunk, Quantitative x-ray phase nanotomography, Phys. Rev. B. 85 (2012) 020104. https://doi.org/10.1103/PhysRevB.85.020104.

[25] M. Trini, P.S. Jørgensen, A. Hauch, M. Chen, P.V. Hendriksen, Microstructural Characterization of Ni/YSZ Electrodes in a Solid Oxide Electrolysis Stack Tested for 9000 Hours, ECS Trans. 78 (2017) 3049-3064. https://doi.org/10.1149/07801.3049ecst.

[26] J.T. Richardson, R. Scates, M.V. Twigg, X-ray diffraction study of nickel oxide reduction by hydrogen, Appl. Catal. Gen. 246 (2003) 137-150. https://doi.org/10.1016/S0926860X(02)00669-5.

[27] T.A. Utigard, M. Wu, G. Plascencia, T. Marin, Reduction kinetics of Goro nickel oxide using hydrogen, Chem. Eng. Sci. 60 (2005) 2061-2068. https://doi.org/10.1016/j.ces.2004.11.024. 

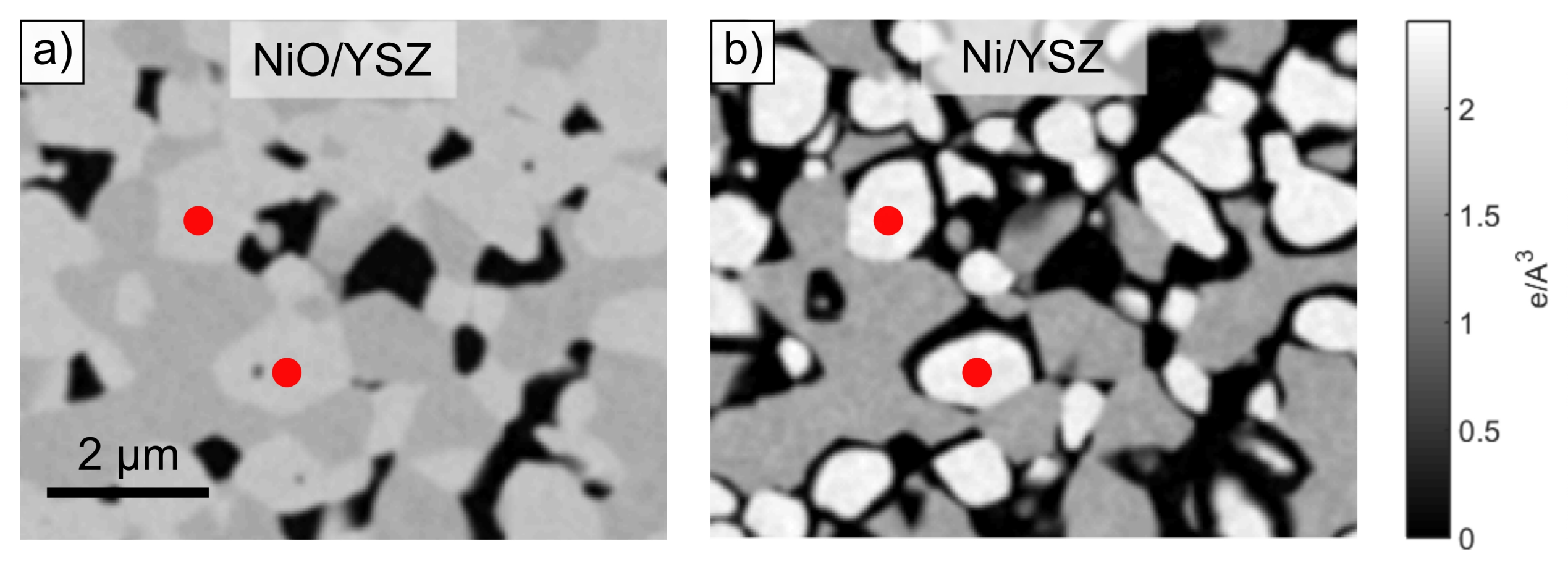
a)

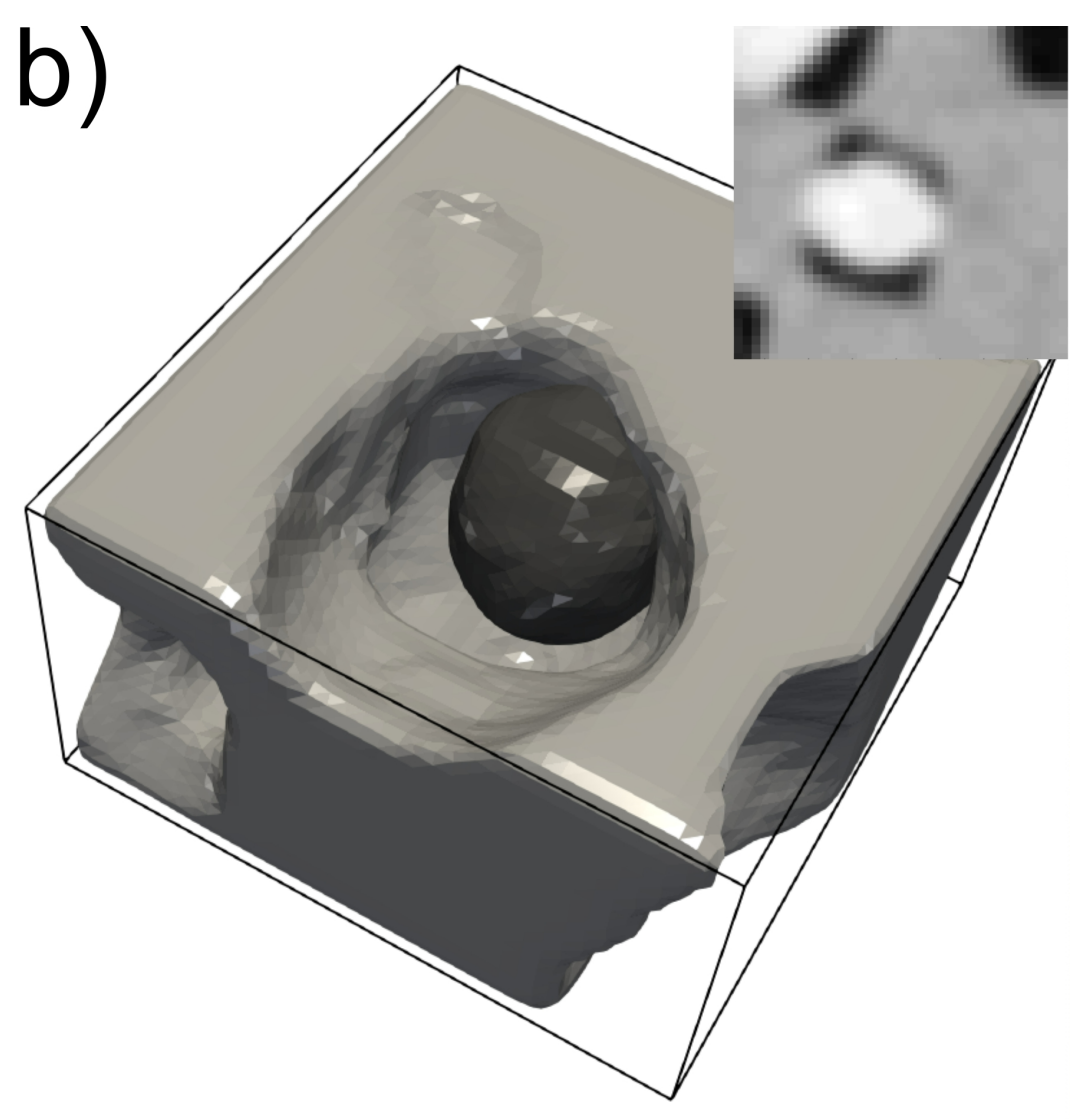

$\mathrm{NiO}$

YSZ

$\mathrm{Ni}$ 

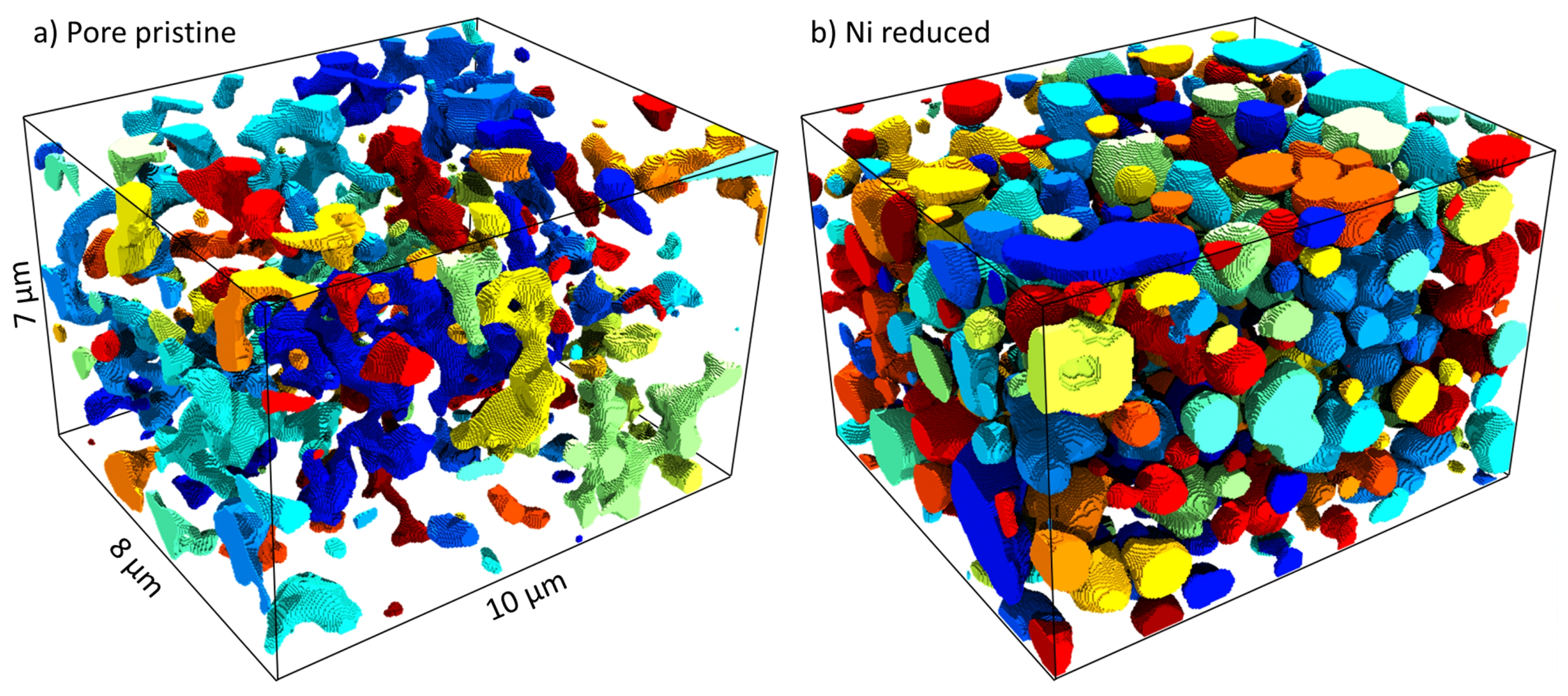


\begin{tabular}{lccc}
\hline & $\begin{array}{c}\text { Pristine } \\
\text { NiO-YSZ }\end{array}$ & $\begin{array}{c}\text { Reduced } \\
\text { Ni-YSZ }\end{array}$ & $\begin{array}{c}\text { Relative } \\
\text { difference [\%] }\end{array}$ \\
\hline Phase fractions & 0.48 & 0.29 & -39 \\
(NiO/Ni) [-] & 0.41 & 0.41 & 0 \\
YSZ [-] & 0.11 & 0.30 & 172 \\
Pore [-] & 0.99 & 0.00 & - \\
Connected (NiO/Ni) $[-]^{*}$ & 0.99 & 0.99 & 0 \\
Connected YSZ [-] & 0.00 & 0.99 & - \\
Connected Pores [-] & & & \\
\hline Volume-specific surface areas $^{*}$ & 0.48 & 1.68 & 250 \\
Pore/YSZ interface $\left[\mu \mathrm{m}^{2} / \mu \mathrm{m}^{3}\right]$ & 0.54 & 1.42 & 162 \\
Pore/(NiO-Ni) interface $\left[\mu \mathrm{m}^{2} / \mu \mathrm{m}^{3}\right]$ & 1.52 & 0.41 & -73 \\
${\text { (NiO-Ni)/YSZ interface }\left[\mu \mathrm{m}^{2} / \mu \mathrm{m}^{3}\right]}_{\text {Pore interface }\left[\mu \mathrm{m}^{2} / \mu \mathrm{m}^{3}\right]}$ & 1.01 & 3.11 & 207 \\
YSZ interface $\left[\mu \mathrm{m}^{2} / \mu \mathrm{m}^{3}\right]$ & 1.99 & 2.10 & 5 \\
${\text { (NiO-Ni) interface }\left[\mu \mathrm{m}^{2} / \mu \mathrm{m}^{3}\right]}_{\text {TPB densities }}$ & 2.07 & 1.84 & -11 \\
\hline Total $\left[\mu \mathrm{m} / \mu \mathrm{m}^{3}{ }^{* *}\right.$ & & & 43 \\
Percolating $\left[\mu \mathrm{m} / \mu \mathrm{m}^{3}{ }^{*}\right.$ & 2.34 & 3.35 & - \\
\hline
\end{tabular}

* Relative difference not defined here.

$* *$ The pristine column refers to the density of the NiO-YSZ-Pore triple phase boundaries 


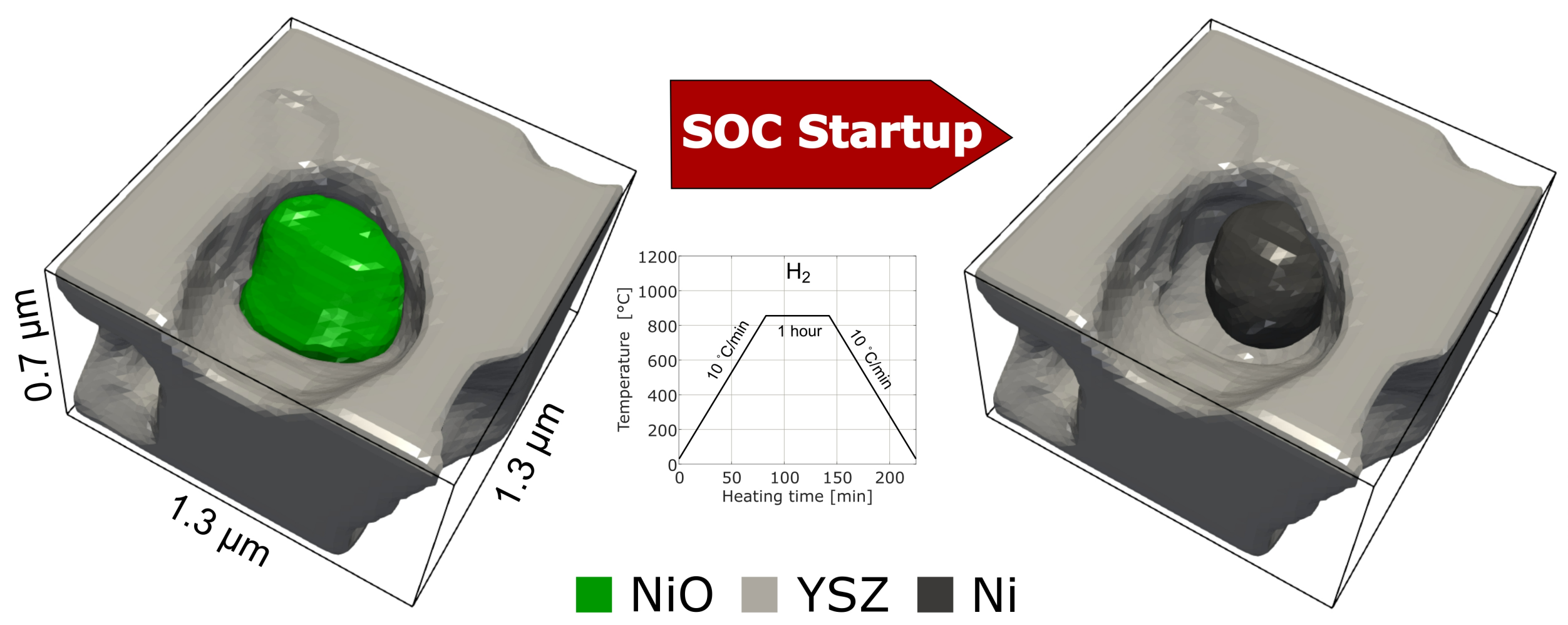

